\title{
FINITE ELEMENT METHOD ANALYSIS OF THICKNESS OF PLATES
}

\author{
K. BABITHA ${ }^{1}$, A. B. S. DADAPEER ${ }^{2}$, G. VENKATA RAMANA ${ }^{3}$ \\ \& V MADHAVI NAGI REDDY ${ }^{4}$ \\ ${ }^{1,3}$ Institute of Aeronautical Engineering, Hyderabad, Telangana, India \\ ${ }^{2}$ Chiranjeevi Reddy Institute of Engineering \& Technology, Anantapur, Andhra Pradesh, India \\ ${ }^{4}$ Marri Laxman Reddy Institute of Technology, Hyderabad, Telangana, India
}

\begin{abstract}
The advance in the improvement of using structural components for the aerospace structure is essential and their importance in the fields of engineering especially in the construction of bridges, floor panels and in the field of the aeronautical domain in the design of the wings and sheet panels. The main objective here is to find the optimum design thickness of the plates. Initially, the optimized selection of the material is chosen and then thickness analysis is carried using the numerical analysis. The results obtained are validated with optimized Computational results. Finally coming out with the improvised live load carrying capacity of the material.

KEYWORDS: Deflection, Shear Wall, ANSYS, Soffit \& Plate etc
\end{abstract}

Received: Apr 03, 2018; Accepted: May 23, 2018; Published: Jun 04, 2018; Paper Id.: IJMPERDJUN201888

\section{INTRODUCTION}

\section{Introduction about Plate}

Consider a four-noded quadrilateral component with 12-degrees-of-freedom and Each hub has 3 degrees of freedom, one displacement and two rotations.

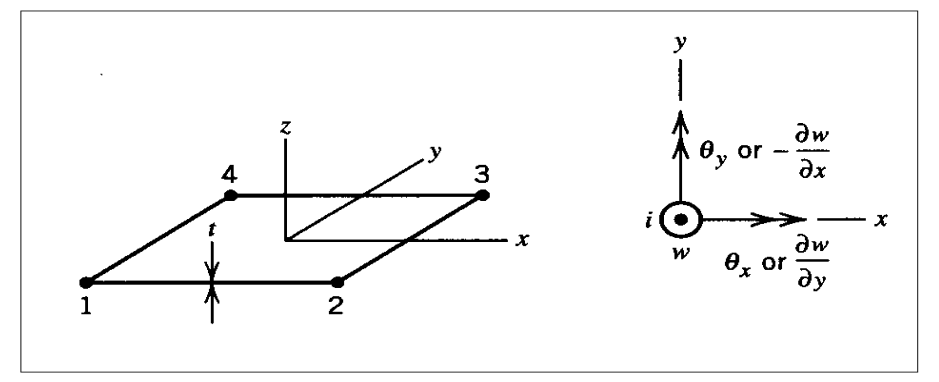

Figure 1: Noded -Quadrilateral Plate Element

To play out the investigation under the ANSYS programming the basic conduct of the component is considerd as direct. Type of material is Aluminium composite 6005 T6 Shape of a component is the rectangle.

\section{METHODS FOR THE ANALYSIS OF PLATE}

\section{Thin Plate Theory}

Considering thin plate theory with small deflections and the assumptions made were no deflection in the middle of the plate, points of the plate lying initially on a normal to the middle surface of the plate remain on the normal to the surface even after bending. 


\section{Kirchoff's Thin Plate Theory}

Generally, Kirchhoff's plate hypothesis takes after with three assumptions, used to reduce the equations of threedimensional theory of elasticity to two dimensions.

\section{Assumptions}

Assumptions like

The line which is normal to the neutral axis remains straight after bending.

Normal stresses which are in the thickness direction neglected $\sigma_{\mathrm{z}}=0$.

Transverse shearing strains are considered to be zero where shear strains become zero.

The above assumptions are graphically shown in Figure

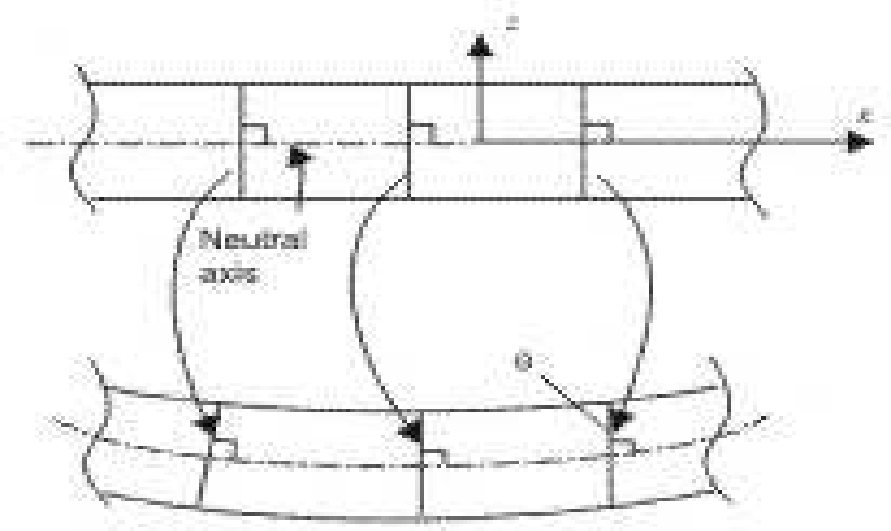

Figure 2: Kirchhoff Plate after Bending

\section{Governing Equation for Deflection}

Consider a differential slice which is cut from the plate via planes opposite to the $\mathrm{x}$-axis as shown in Figure. loading q makes a plate deform laterally or upward in the $\mathrm{z}$-direction, and the deflection $\mathrm{w}$ of point $\mathrm{P}$ is assumed to the function of $\mathrm{x}$ and $\mathrm{y}$; that is, $\mathrm{w}=\mathrm{w}(\mathrm{x}, \mathrm{y})$ and the plate does not extend in the $\mathrm{z}$-direction. A line is drawn from the plate surface before loading remains perpendicular to the surfaces after loading.
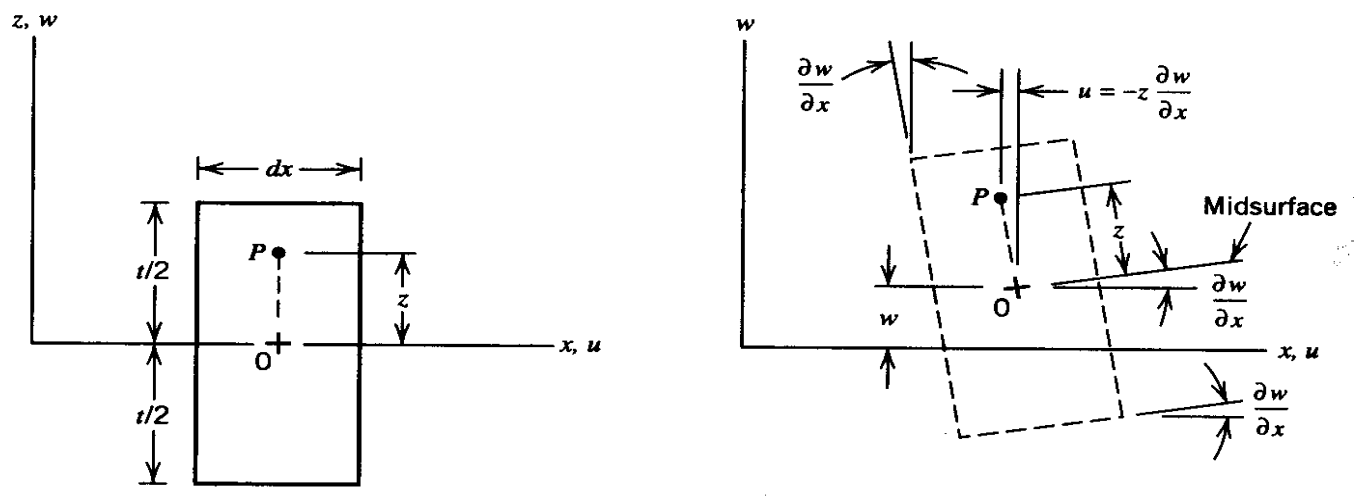

Figure 3: Differential Slice of Plate of Thickness $t$ (a) Before Loading and (b) Displacements of Point $P$ after Loading, based on Kirchhoff Theory 


\section{ANSYS ANALYSIS OF ALUMINIUM DECK PLATE WITH CLAMPED EDGES}

\section{Pre-Processor}

\section{Element Type}

Since it is a 3- dimensional problem (because of the out of plane vibration modes of the plate), we will need a shell element rather than a simple 2D-quadrilateral.

- On the preprocessor menu, click on 'Element Type'.

- Click on 'Add/Edit/Delete.

- Click on 'Add'.

- Choose the 'shell' under the structural heading from the list on the left, and Elastic 4 node 63 ' from the list on the right, then click on ' $\mathrm{OK}$ '.

\section{Real Constants}

The plate thickness is necessary to solve this problem, and is input as a real constant.

- Click on 'Real constants' on the preprocessor menu.

- Click on 'Add'.

- Click 'OK' in the element type for a Real constants box ( there is only the one element type t o define Real constants for).

- Enter the $0.01 \mathrm{~m}(10 \mathrm{~mm})$ in all four boxes for shell thickness, then click 'OK'.( it is possible to define different thicknesses for different nodes on the plate, but we will choose a plate of uniform thickness here.)

\section{Material Properties}

We will use generic values for aluminum for this problem

- Click on 'Material properties' on the preprocessor menu.

- Click on 'Material props' then click 'OK'.

- Double-click on ' Structural' in the right side of the window, then 'Linear', then 'Elastic', then finally 'Isotropic'.

- Enter the 70e9 (70 Gpa) for young's modulus, and 0.3 for poison's ratio, then click ' OK'.

- Double-click on 'Density; in the right side of the window, then enter $2.7 \mathrm{e} 3$ (2700 kg/cubic meter) for the material's density and click 'OK'.

\section{Modeling}

Now we will create the model

- Under the - 'modeling'-heading on the preprocessor menu, click on ' create'.

- Under the - ' areas'- heading, click on 'Rectangle'.

- Click on 'By dimensions'. 
- Enter the following values:

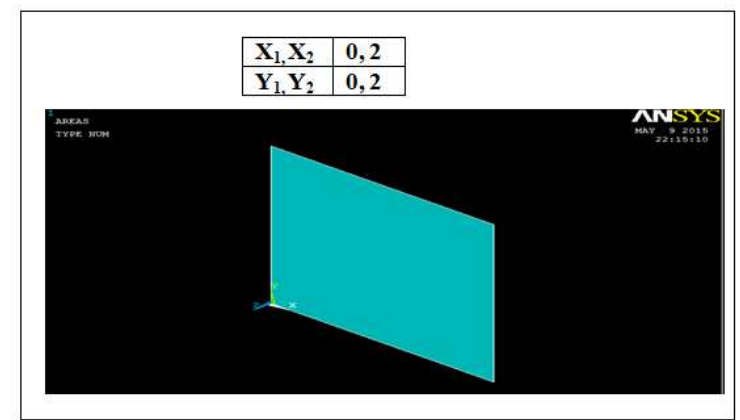

Figure 4: Aluminum Alloy 2m X 2m Plate Element

\section{Meshing}

- On the preprocessor menu, click on 'Mesh tool'.

- Under lines in the size controls section, click on 'Set'.

- In the pick box, click on 'Pick all'.

- Enter the 20 into the box for the number of element divisions, then click 'OK'.

- In the Mesh Tool box, click on 'Mesh' in the pick box that appears, click on 'Pick All'. ANSYS will now mesh the model.

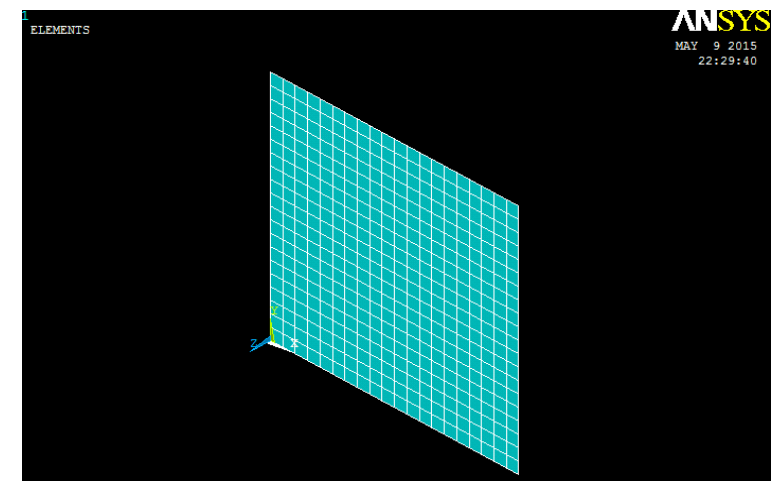

Figure 5: Plate with Mesh

\section{Solution}

Defining the Analysis

- On the solution menu, click on 'New analysis'.

- Choose the 'Static' option then click 'OK'.

- On the solution menu, click 'Analysis Options'.

- Enter the 5 in the box for number of modes to extract and set the mode extraction method to 'Subspace', then click 'OK'. Since we have defined a fairly fine mesh, we have easily get accurate results for this many modes.

- Click 'OK' in the box for subspace modal analysis options. 


\section{Applying Boundary Conditions}

- On the solution menu under the loads heading, click on 'Apply'.

- Click on 'structural'.

- Click on 'Displacement'.

- Click 'on lines'.

- Click on all sides of the plate, then select 'ALL DOF', then click ok.

\section{Apply the Force/Moment}

- On the solution menu under the loads heading, click 'Apply'.

- Click on 'structural'.

- $\quad$ Click on 'Force/moment'.

- $\quad$ Click 'on nodes'.

- $\quad$ Click on center node of the plate, then click 'OK'.

- Select the 'Fz' as direction of force and give the force/moment value as $100 \mathrm{KN}$

\section{RESULTS AND DISCUSSIONS}

\section{Results}

The analysis of aluminum alloy 6005 T6 deck plate has been carried out using the standard AASTHO specifications, according to this code, the maximum deflection should be less than or equal to L/800.

$$
\text { i.e., } \begin{aligned}
\Delta_{\max } & \leq \mathrm{L} / 800 \\
& \leq 2000 / 800 \\
\Delta_{\max } & \leq 2.5 \mathrm{~mm}
\end{aligned}
$$

Where $\mathrm{L}$ is the length of the element.

\section{Live Load}

The live load has been adopted as $100 \mathrm{kN}$

\section{Result From ANSYS}

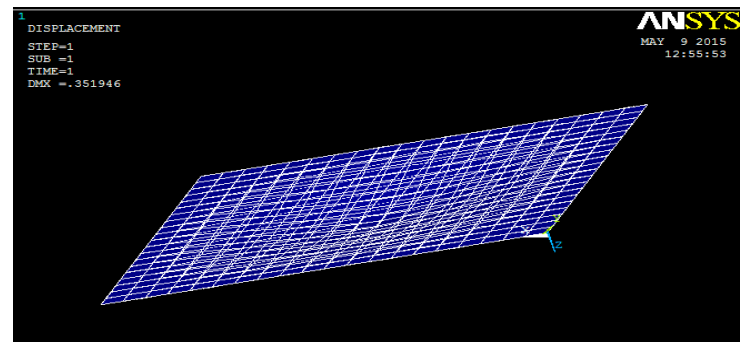

Figure 6: Deformed Shape for $0.01 \mathrm{~m}$ Thickness of the Plate 
From the above figure 6 the maximum deflection of the plate is $351.9 \mathrm{~mm}$, this value is greater than the $2.5 \mathrm{~mm}$, hence the structure is not safe under a thickness of $0.01 \mathrm{~m}$.

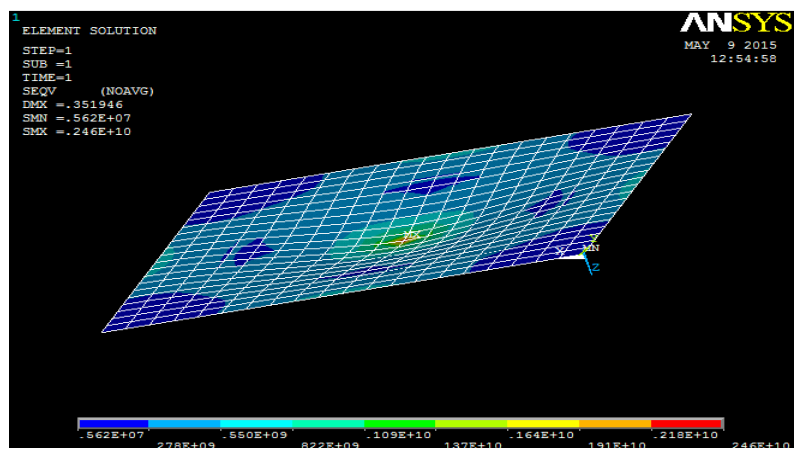

Figure 7: Stress Profile for $0.01 \mathrm{~m}$ Thickness of the Plate

We should use the material properties for the cross-checking of stress. they are 1.1 for proof stress and 1.25 for tensile strength( adopted from Euro code EN 1999-1-1) then the final stresses are as follows

- $\quad 0.2 \%$ proof stress $=215 / 1.1=195 \mathrm{~N} / \mathrm{mm}^{2}$

- $\quad$ Ultimate tensile strength $=115 / 1.25=92 \mathrm{~N} / \mathrm{mm}^{2}$

From the above figure we can observe that the max stress of the plate is $2.46 \mathrm{KN} / \mathrm{mm}^{2}$, to get the design value, it should be multiplied by the combination factor 1.5 , then the design stress value is $3690 \mathrm{~N} / \mathrm{mm}^{2}$. The unit check for stress is, $3690 / 195=18.92$, this value is greater than 1 . Similarly, the design ultimate tensile strength of HAZ is $3690 / 92=40.1$, this is also greater than 1 , hence the structure is not safe for the $0.01 \mathrm{~m}$ thickness of the plate.

\section{CONCLUSIONS}

From the results, it can be concluded that the optimized chosen material with desired specific thickness obtained that is aluminum alloy $2 \mathrm{~m} \mathrm{X} 2 \mathrm{~m}$ plate element with thickness results are examined and found that the structure is not safe at a $0.01 \mathrm{~m}$ thickness of the plate. The structure is analyzed using numerical analysis by thin plate theory. The computational analysis is carried out using ANSYS software. The stresses found to be $2.46 \mathrm{KN} / \mathrm{mm}^{2}$. To get the design value, it should be multiplied by combination factor 1.5 , then the design stress value is $3690 \mathrm{~N} / \mathrm{mm}^{2}$. The unit check for stress is, $3690 / 195=$ 18.92, this value is greater than 1. Similarly, the design ultimate tensile strength of HAZ is $3690 / 92=40.1$, this is also greater than 1 ; Hence the structure is not safe for the $0.01 \mathrm{~m}$ thickness of the plate.

\section{REFERENCES}

1. SEMIE, ADDISU GEZAHEGN. "Numerical Modeling of Thin Plates using the Finite Element Method." Addis Ababa University (2010).

2. VANAM, B. C. L., M. RAJYALAKSHMI, AND R. INALA. "Static analysis of an isotropic rectangular plate using finite element analysis (FEA)." Journal of Mechanical Engineering Research4, no. 4 (2012): 148-162.

3. S. LOKESH, GS VIVEK. "Buckling Analysis Of Laminated Composite Plates Using Layer wise Higher Order Shear Deformation Theory”. International Journal of Mechanical and Production Engineering Research and Development (2010)

4. S. LOKESH, DR C H LAKSHMI TULASI. "Vibration analysis of laminated composite plates using layer wise higher order shear deformation theory”. International Journal of Mechanical Engineering and Technology, (2017) 